\title{
Quantitative analysis of povidone-iodine thin films by X-ray photoelectron spectroscopy and their physicochemical properties
}

\author{
ANONGTIP SA ${ }^{1}$ \\ SOMCHAI SAWATDEE 2 ,* \\ NARUBODEE PHADOONGSOMBUT ${ }^{3}$ \\ WILAIPORN BUATONG ${ }^{4}$ \\ TITPAWAN NAKPENG ${ }^{4}$ \\ RUTTHAPOL SRITHARADOL \\ TEERAPOL SRICHANA ${ }^{1,4, *}$ \\ ${ }^{1}$ Department of Pharmaceutical \\ Technology, Faculty of Pharmaceutical \\ Sciences, Prince of Songkla University \\ Hat Yai, Songkhla 90112, Thailand \\ ${ }^{2}$ Drug and Cosmetic \\ (Research and Development Unit), \\ School of Pharmacy, Walailak University \\ Thasala, Nakhon Si Thammarat 80161 \\ Thailand \\ ${ }^{3}$ Department of Pharmaceutical \\ Chemistry, Faculty of Pharmaceutical \\ Sciences, Prince of Songkla University \\ Hat Yai, Songkhla 90112, Thailand \\ ${ }^{4}$ Nanotec-PSU Excellence Center \\ on Drug Delivery System \\ Faculty of Pharmaceutical Sciences \\ Prince of Songkla University, Hat Yai \\ Songkhla 90112, Thailand
}

\begin{abstract}
In this study, povidone-iodine (PVP-I) has been formulated as a topical spray to produce a thin film for the controlled release of $\mathrm{I}_{2}$. By means of experimental design, 27 formulations containing glycerol, ethanol, PEG 400, copovidone and HFA 134a as a propellant were prepared. The $\mathrm{pH}$ values of all formulations were in the range of $6-7$. The viscosity was within the range of $11.9-85.9 \mathrm{mPa}$. The surface tensions were 20.3 to $24.6 \mathrm{mN} \mathrm{m}^{-1}$ and the contact angles were between 19.3 and $38.7^{\circ}$. The assays for the iodine contents were within acceptable range (80-120\%). X-ray photoelectron spectroscopy analysis revealed the ionized form of iodine was much higher than the unionized form. The MIC and $M B C$ values of the PVP-I sprays against Staphylococcus aureus, S. epidermidis and Pseudomonas aeruginosa were higher than that of commercial PVP-I solution. The cytotoxicity study confirmed that the PVP-I spray had lower toxic effects on keratinocytes and fibroblasts compared to the commercial PVP-I solution. The formulation containing $59 \%$ ethanol, $18 \%$ copovidone and 12 \% PEG 400 showed good antibacterial activity.
\end{abstract}

Keywords: povidone-iodine, topical spray, bioactivity, cytotoxicity, X-ray photoelectron spectroscopy

Human skin harbors many kinds of bacteria, including potential pathogenic bacteria such as Staphylococcus aureus, Streptococcus pyogenes, S. epidermidis, Pseudomonas aeruginosa and even some anaerobic bacteria such as Clostridium spp. that could induce tetanus. These microbes can initiate diseases such as gangrene and dermatitis, when the skin is damaged (1). At procedural and surgical sites, bacteria can create infections that lead to complex

\footnotetext{
*Correspondence; e-mail addresses: teerapol.s@psu.ac.th, somchai.sa@wu.ac.th, somchai086@hotmail.com
} 


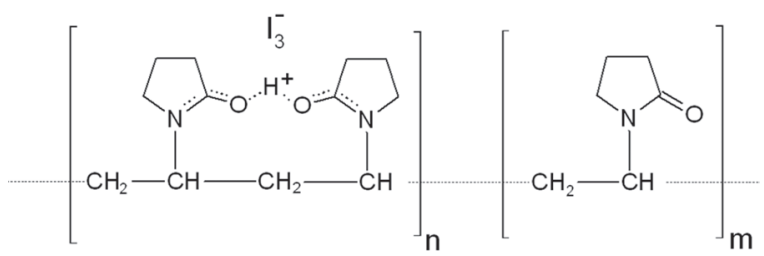

Fig. 1. Chemical structure of povidone-iodine (PVP-I).

clinical scenarios. Hence, the skin surface must be carefully disinfected prior to any procedure.

Iodine is one of the most effective antiseptics, commonly used as an antimicrobial agent as it has bactericidal, fungicidal and viricidal properties (2). It has been used for the prevention or management of wound infections for over 150 years. However, there are several problems associated with the use of iodine as an antiseptic $(3,4)$. Iodine is unstable and partially soluble in water. Its solution can irritate the skin and is capable of causing tissue damage (5). The use of an iodine tincture has been replaced by povidone-iodine (PVP-I) (6) (Fig. 1). This is a loose complex of molecular iodine and polyvinylpyrrolidone. PVP-I a neutral, amphipathic organic compound that serves as a sustained release reservoir for iodine. PVP-I is one of the most popular topical antiseptics because of iodine's ability to kill both Gram-positive and Gram-negative bacteria and it is cheap.

However, the toxicity of iodine is related to the presence of unionized iodine $\left(\mathrm{I}_{2}\right)$ and a tri-iodide complex $\left(\mathrm{I}_{3}^{-}\right)$. The complexation and dissociation of the iodine complex from PVP-I occur as described in the following equations (7).

$$
\begin{aligned}
& \mathrm{PVP}+\mathrm{I}_{2} \longrightarrow k_{1} \longrightarrow \mathrm{PVP}_{2} \\
& \mathrm{PVP}^{-\mathrm{I}_{2}} \longrightarrow \mathrm{k}_{2} \longrightarrow \mathrm{PVP} \mathrm{I}^{+} \mathrm{I}^{-} \\
& \mathrm{PVP}^{+} \mathrm{I}^{-} \longrightarrow k_{3} \longrightarrow \mathrm{PVP}^{-} \mathrm{I}^{+}+\mathrm{I}^{-} \\
& 2 \mathrm{PVP}^{+} \mathrm{I}^{+} \mathrm{I}^{-} \stackrel{k_{4}}{\longrightarrow}(\mathrm{PVP})_{2} \mathrm{I}^{+}+\mathrm{I}_{3}^{-}
\end{aligned}
$$

$\mathrm{I}_{2}$ has a higher toxicity on the skin than $\mathrm{I}_{3}{ }^{-}$or ionized iodine $\left(\mathrm{I}^{+}\right.$or $\left.\mathrm{I}^{-}\right)(5)$. Avoidance of a high concentration of $\mathrm{I}_{2}$ can be achieved by the use of a PVP-I solution. Topical formulations of PVP-I are available in the form of ointments, sprays, or lotions to prevent microbial contamination of wounds, ulcers, burns, etc. PVP-I effectively controls bacterial growth and protects the developing epithelium. Almost all iodine preparations in solution need cotton or gauze for the application. Iodine in solution makes patients suffer from pain when dressing the wound (6). PVP-I administered as a spray preparation could overcome these problems. The advantages of a PVP-I spray are their safety, time-saving, effectiveness as antiseptic and germicide for surgery, burns and stasis ulcers. A spray can be applied directly to the wound and will dry in a short time, so there is no need to use cotton or gauze to spread or cover the wound. A spray preparation of PVP-I can be more effective if an excipient such as a humectant and a film forming agent are added to enhance the bactericidal effects with the convenience of direct application to the skin (8). 
Due to these potential benefits, PVP-I has been formulated as a topical spray to produce a thin film for the controlled release of $\mathrm{I}_{2}$ to alleviate the toxicity. The aim of this research has focused on the preparation and evaluation of a thin film PVP-I spray and analysis of the $\mathrm{I}_{2}$ and $\mathrm{I}_{3}^{-}$by an X-ray photoelectron spectroscopy (XPS) technique.

\section{EXPERIMENTAL}

\section{Materials}

PVP-I, $\mathrm{I}_{2}$ and polyethylene glycol 400 (PEG 400) were obtained from Srichand United Dispensary (Thailand). Commercial PVP-I solution (Siribuncha ${ }^{\circledR}$ ) was obtained from Siribuncha Co. Ltd. (Thailand). Iodine spray made in house (1\% iodine available) was compared with PVP-I spray in X-ray photoelectron spectroscopy. Copovidone (Kollidon ${ }^{\circledR}$ VA64) and glycerol were purchased from BASF (Germany) and the PC Drug Center, Bangkok, Thailand respectively. Ethanol (absolute) and HFA 134a propellant were purchased from V.S. Chem. House (Thailand) and Mexichem (UK), respectively. Mannitol salt agar was obtained from Merck (Germany). Brain heart infusion (BHI) broth was obtained from Becton, Dickinson and Company (USA). Resazurin sodium was obtained from Sigma-Aldrich (USA) and MTT was purchased from Invitrogen ${ }^{\mathrm{TM}}$, Thermo Fisher Scientific (Germany).

\section{Bacterial strains}

The Gram-positive (Staphylococcus aureus and S. epidermidis) and Gram-negative (Pseudomonas aeruginosa) bacteria of ATCC and clinical origin were selected for this study because they are predominantly involved in wound infections (9). S. aureus (ATCC 25923, USA), P. aeruginosa (ATCC 27853, USA) and S. epidermidis (TISTR17) were received from the Thailand Institute of Scientific and Technological Research (Thailand). Clinical isolates of S. aureus, S. epidermidis and P. aeruginosa were collected from Songklanagarind Hospital, Hat Yai, Songkhla, Thailand.

\section{Dielectric constant measurements}

The dielectric constants $(\varepsilon)$ of all ingredients were measured to predict the solubility of the PVP-I formulation system using an Agilent 4284A precision inductance capacitance resistance meter (Agilent Technologies, Inc., Japan). In a solution-based formulation, the $\varepsilon$ of a solvent system affects the solubility of the drug. Therefore, the content and uniformity of the drug must be taken into account based on the degree of difference in their $\varepsilon$ values. The dielectric constant of a mixed solvent $\left(\varepsilon_{\text {mixture }}\right)$ was calculated according to the individual $\varepsilon$.

$$
\varepsilon_{\text {mixture of } \mathrm{A}, \mathrm{B} \text { and } \mathrm{C}}=\varphi(\mathrm{A}) \varepsilon_{\mathrm{A}}+\varphi(\mathrm{B}) \varepsilon_{\mathrm{B}}+\varphi(\mathrm{C}) \varepsilon_{\mathrm{C}}
$$

where $\varepsilon_{\text {mixture }}$ is the $\varepsilon$ of the mixture of solvent, $\varepsilon_{\mathrm{A}}, \varepsilon_{\mathrm{B}}, \varepsilon_{\mathrm{C}}$, are the $\varepsilon$ of the solvent $\mathrm{A}$, solvent $\mathrm{B}$ and solvent $\mathrm{C}$, respectively, and $\varphi(\mathrm{A}), \varphi(\mathrm{B}), \varphi(\mathrm{C})$ are the ratio of the solvent in the mixed solution $(\%, V / V)(10,11)$.

\section{Formulation design}

A three level factorial design was applied to investigate the effects of the three factors: concentration of ethanol, copovidone and PEG 400, on the physicochemical properties of 
A. Sa et al.: Quantitative analysis of povidone-iodine thin films by X-ray photoelectron spectroscopy and their physicochemical properties, Acta Pharm. 67 (2017) 169-186.

Table I. Composition of the PVP-I formulations F1-F27

\begin{tabular}{|c|c|c|c|c|c|}
\hline \multirow{2}{*}{ Formulation } & \multicolumn{5}{|c|}{ Ingredients $(\%, m / m)$} \\
\hline & PVP-I & Glycerol & Ethanol & Copovidone & PEG 400 \\
\hline F1 & 10 & 1 & 59 & 16 & 14 \\
\hline $\mathrm{F} 2$ & 10 & 1 & 59 & 10 & 20 \\
\hline F3 & 10 & 1 & 59 & 7 & 23 \\
\hline $\mathrm{F} 4$ & 10 & 1 & 59 & 20 & 10 \\
\hline F5 & 10 & 1 & 59 & 14 & 16 \\
\hline F6 & 10 & 1 & 59 & 12 & 18 \\
\hline F7 & 10 & 1 & 59 & 23 & 7 \\
\hline F8 & 10 & 1 & 59 & 18 & 12 \\
\hline F9 & 10 & 1 & 59 & 15 & 15 \\
\hline F10 & 10 & 1 & 69 & 10 & 10 \\
\hline F11 & 10 & 1 & 69 & 7 & 13 \\
\hline F12 & 10 & 1 & 69 & 4 & 16 \\
\hline $\mathrm{F} 13$ & 10 & 1 & 69 & 5 & 15 \\
\hline F14 & 10 & 1 & 69 & 13 & 7 \\
\hline F15 & 10 & 1 & 69 & 6 & 14 \\
\hline F16 & 10 & 1 & 69 & 11 & 9 \\
\hline F17 & 10 & 1 & 69 & 9 & 11 \\
\hline F18 & 10 & 1 & 69 & 8 & 12 \\
\hline F19 & 10 & 1 & 79 & 1 & 9 \\
\hline F20 & 10 & 1 & 79 & 1.5 & 8.5 \\
\hline F21 & 10 & 1 & 79 & 2 & 8 \\
\hline F22 & 10 & 1 & 79 & 2.5 & 7.5 \\
\hline F23 & 10 & 1 & 79 & 3 & 7 \\
\hline F24 & 10 & 1 & 79 & 3.5 & 6.5 \\
\hline F25 & 10 & 1 & 79 & 4 & 6 \\
\hline F26 & 10 & 1 & 79 & 4.5 & 5.5 \\
\hline F27 & 10 & 1 & 79 & 5 & 5 \\
\hline
\end{tabular}

All formulations were adjusted to the ratio of all ingredients to make a volume of $4 \mathrm{~mL}$, then were mixed with $8 \mathrm{~mL}$ of the HFA 134a propellant and the final volume of the PVP-I spray was $12 \mathrm{~mL}$.

the formulation. All PVP-I formulations contained $10 \%(\mathrm{~m} / \mathrm{m})$ PVP-I and $1 \%(\mathrm{~m} / \mathrm{m})$ glycerol. Ethanol was used as a co-solvent with a concentration of 59, 69 and $79 \%(\mathrm{~m} / \mathrm{m})$. The concentrations of PEG 400, ethanol and copovidone are listed in Table I to make a total 27 formulations.

\section{Evaluation of the PVP-I topical spray}

Density and viscosity

The density of PVP-I solution was measured using a $25 \mathrm{~mL}$ pycnometer. The viscosity of the PVP-I solution was measured using a Brookfield viscometer (model LV-DV-II, Helipatch-spindle type S-96, Brookfield Engineering (Germany). 


\section{Surface tension}

Surface tension was measured using a contact angle meter OCA 15 EC (Dataphysics Instruments $\mathrm{GmbH}$, Germany). Measurements of the surface tension were made using a drop shape analysis. The angle meter released the solution through a small needle. The shape and form of the solution at the tip of the needle was recorded with a high-resolution camera. The equipment recorded the shape and density of the droplets to calculate the surface tension.

\section{Contact angle}

The static sessile drop method was measured using the contact angle meter. The angle formed between the liquid/air interface was the contact angle. Current-generation systems employ high-resolution cameras and software to capture and analyze the contact angle. The droplet was deposited by a syringe pointed vertically down onto the sample surface, and a high-resolution camera captured the image, which was then analyzed using image analysis software. The size of the droplet was increased gradually so that it grew proportionally, and the contact angle remained constant. By taking pictures incrementally as the droplet grows, the user can acquire a set of data to obtain an average value.

\section{Evaporation time}

The time needed for the spray film to dry was estimated by spraying PVP-I formulations onto a glass slide at a $10 \mathrm{~cm}$ distance from the slide. The time taken for complete evaporation was recorded.

\section{Preparation of the PVP-I topical spray}

All formulations contained PVP-I at a concentration of $10 \%(\mathrm{~m} / \mathrm{m})$. Other ingredients were absolute ethanol, glycerol, PEG 400 and copovidone at various concentrations. Four $\mathrm{mL}$ of the formulation was pipetted into a glass canister (Schott AG, Germany). Then a $50 \mu \mathrm{L}$ metering valve was immediately crimp-sealed onto the canister with an aerosol crimping and filling machine (model 2016, Pamasol Willi Mäder, Switzerland). The canisters were then filled with a specified amount of propellant $(8 \mathrm{~mL})$.

\section{Evaluation of the $\mathrm{pH}$ of the PVP-I spray}

A non-aqueous probe (Thermo Fisher Scientific, USA) was used to measure the $\mathrm{pH}$ of the spray formulation (12). The PVP-I spray was discharged three times to sufficiently cover the probe at a distance of $10 \mathrm{~cm}$. The $\mathrm{pH}$ was recorded $30 \mathrm{~s}$ after spraying. The probe was washed with distilled water and dried. Three replications were performed for each formulation.

\section{Stability of the PVP-I spray}

A physical stability was performed after the formulations were stored for a short period $\left(1\right.$ and 3 months at $25^{\circ} \mathrm{C}$ ). The spray was kept in a clear canister to monitor the sedimentation of iodine. The leakage of the product was evaluated by monitoring the mass loss of the canister.

Measurement of the iodine content in the PVP-I spray formulations

Before testing, the formulation was shaken for $30 \mathrm{~s}$ and the first two doses were discharged. Then the stainless steel base plate with a central hole to collect aerosol samples 
A. Sa et al.: Quantitative analysis of povidone-iodine thin films by X-ray photoelectron spectroscopy and their physicochemical properties, Acta Pharm. 67 (2017) 169-186.

was placed in a 50-mL beaker filled with $10 \mathrm{~mL}$ ethanol (13). Ten sprays at the beginning, middle and the end of the total number of doses were discharged into the solvent. The amount of iodine was analyzed titrimetrically with standardized sodium thiosulfate as described in the United States Pharmacopeia (14).

\section{XPS determination of iodine form}

This study was designed to determine the form of iodine in the two types of formulations (PVP-I spray and iodine spray). Iodine spray was made in house by dissolving iodine in hydro-alcoholic solution ( $1 \%$ iodine available) and then filled in spray bottle container. As the ionized and unionized iodine influence the toxicity and antimicrobial activity. We hypothesized that the iodine spray would produce more unionized iodine than the PVP-I. The ratio of ionized and unionized iodine in the PVP-I and iodine sprays were analyzed using the XPS technique (SUT-NANOTEC-SLRI XPS Beamline 5.2, Synchrotron Light Research Institute, Thailand). The spectra were recorded using a PHI 5000 VersaProbe II (ULVAC-PHI, Japan) with an Al K $\alpha(h v=1486.3 \mathrm{eV})$ source. Samples were sprayed onto the glass slide and left in the desiccator for $15 \mathrm{~min}$ to completely dry the samples prior to analysis. The pressure in the analyzer chamber was kept below $10^{-8} \mathrm{mbar}$ during analysis. For calibration purposes, the $\mathrm{C} 1 \mathrm{~s}$ line $(\mathrm{B} . \mathrm{E}=284.5 \mathrm{eV})$ was used.

\section{Distribution of the droplet size and thickness of the PVP-I topical spray}

The PVP-I spray was discharged onto the glass slide at a distance of $10 \mathrm{~cm}$. After the droplets had been deposited on the glass slide, the drop size was measured using a microscope (Olympus BX61, Japan) (15). The morphology and thickness of the PVP-I thin films were observed by atomic force microscopy (AFM) (Nanosurf easyScan 2, NANOSURF AG, Switzerland). AFM imaging was performed using non-contact mode.

\section{Antibacterial activity of the PVP-I topical spray formulation}

The antimicrobial activity of PVP-I spray (formulation F8) and commercial PVP-I solution (Siribuncha ${ }^{\circledR}$ ) was analyzed using the disc diffusion method. Bacterial strains (clinical isolates) of $S$. aureus, S. epidermidis, and P. aeruginosa were grown in $\mathrm{BHI}$ broth. Overnight grown bacterial cultures were centrifuged $\left(4,000 \mathrm{rpm}\right.$ for $10 \mathrm{~min}$ at $\left.4{ }^{\circ} \mathrm{C}\right)$ and the pellets were suspended in phosphate buffered saline ( $\mathrm{pH} 7.4)$ with a turbidity equivalent to 0.5 McFarland standard resulting in an approximate of $10^{8} \mathrm{CFU} \mathrm{mL} \mathrm{m}^{-1}$. Bacterial inoculum (150 $\mathrm{mL}$ ) was added to $15 \mathrm{~mL}$ of molten $\mathrm{BHI}$ agar medium maintained at $50{ }^{\circ} \mathrm{C}$. The medium was rapidly mixed and poured into the petri dish. Paper discs $(6 \mathrm{~mm}$ diameter; Oxoid, Thermo Fisher Scientific, Basing Stoke, England) impregnated with $10 \mu \mathrm{L}$ of the PVP-I spray formulation and Siribuncha ${ }^{\circledR}$ PVP-I solution were placed on the agar surface. Vancomycin $(30 \mu \mathrm{g})$ and gentamicin $(10 \mu \mathrm{g})$ discs were used as positive controls. The plates were incubated at $37^{\circ} \mathrm{C}$ for $18 \mathrm{~h}$ and the zone of growth inhibition was measured.

The minimal growth inhibitory concentration (MIC) was determined by a broth microdilution method (16). Briefly, $100 \mathrm{~mL}$ of the serially diluted PVP-I spray formulation and Siribuncha ${ }^{\circledR}$ PVP-I solution (concentrations varied from 1.25 to $0.039(\%, m / V)$ ) in BHI broth were added to each well of a 96 well plate. Ten microliters of the bacterial suspension $\left(10^{5}\right.$ CFU mL ${ }^{-1}$ ) was added to each well and the plate was incubated at $37^{\circ} \mathrm{C}$ for $18 \mathrm{~h}$. After incubation, $30 \mu \mathrm{L}$ of resazurin sodium salt $\left(0.6 \mathrm{mg} \mathrm{mL}^{-1}\right)$ dissolved in water was added to each well and the plate was further incubated for $4 \mathrm{~h}$ at $37^{\circ} \mathrm{C}$. Formation of a pink color 
indicated bacterial growth and the MIC was determined as the least concentration with no color formation.

To determine the minimum bactericidal concentration $(M B C)$, samples were taken from the wells with less than or equal to the determined MIC. The samples were plated on $\mathrm{BHI}$ agar plates and incubated at $37^{\circ} \mathrm{C}$ for $24 \mathrm{~h}$. The highest dilution (lowest concentration) that showed no bacterial colony was taken as the $M B C$.

\section{Viability of the fibroblast and keratinocyte challenged with PVP-I formulations}

The human skin fibroblast cell line (BJ, ATCC: CRL-2522, VA, USA) and human skin keratinocyte cell line (HaCaT, CLS 300493, Eppelheim, Germany) diluted to $1 \times 10^{5}$ cells $\mathrm{mL}^{-1}$ in Eagle's Minimum Essential Medium (EMEM, Gibco, USA) for BJ and Dulbecco's Modified Eagle's Medium (DMEM, Gibco, USA) for HaCaT, respectively, were seeded into 96 well plates. Both the media were supplemented with $10 \%$ fetal bovine serum (FBS, Gibco, NY, USA), 50 units $\mathrm{mL}^{-1}$ of penicillin and $50 \mu \mathrm{g} \mathrm{mL}^{-1}$ of streptomycin and the plates were incubated at $37^{\circ} \mathrm{C}$ in $5 \% \mathrm{CO}_{2}$. After $24 \mathrm{~h}$, the culture media in the plates were replaced with fresh media. PVP-I spray formulation and the Siribuncha ${ }^{\circledR}$ PVP-I solution at $0.32 \%(\mathrm{~m} / \mathrm{V})$ in fresh medium were added into the culture plate and non-treated cells served as controls. After $24 \mathrm{~h}$ incubation, 3-(4,5-dimethylthiazolyl-2-yl)-diphenyltetrazolium bromide (MTT) assay was performed to evaluate metabolic activity of treated and control cells. Briefly, the cells were treated with $100 \mu \mathrm{L}$ of fresh media along with $50 \mu \mathrm{L}$ of MTT solution $\left(5 \mathrm{mg} \mathrm{mL}^{-1}\right)$ and incubated at $37^{\circ} \mathrm{C}$ under $5 \% \mathrm{CO}_{2}$ for $4 \mathrm{~h}$. After removal of the MTT containing media and addition of $100 \mu \mathrm{L}$ of DMSO, the absorbance was determined by a microplate reader (Biohit 830 , Biohit ${ }^{\circledR}$, Finland) at a wavelength of $570 \mathrm{~nm}$. The percentage of cell proliferation was calculated and compared to the respective controls.

\section{Statistical analysis of the data}

Data, wherever applicable, are presented as a mean value \pm standard deviation (SD) from at least three samples. All statistical comparisons were calculated using the SPSS software version 11.5. The analysis of variance (ANOVA) and paired-sample $t$-test were used for comparison of the data among the formulations. A significance level of $p<0.05$ was considered statistically significant.

\section{RESULTS AND DISCUSSION}

\section{Formulation development and optimization of PVP-I topical spray}

The development of an optimal formulation of PVP-I topical spray was started with the selection of the solvent to dissolve the PVP-I to obtain a clear solution. The basic solvent used for the solution formulation included water and ethanol. We aimed to develop the product as a pressurized topical spray by using HFA 134a as the propellant. Ethanol is a suitable solvent due to its miscibility with the propellant. The excipients in the formulation were copovidone as a film forming agent, PEG 400 and glycerol as humectants and moisturizer, respectively. The $\varepsilon$ value was used to choose an appropriate solvent system. This should have an $\varepsilon$ value close to that of the drug to provide a stable solution. The $\varepsilon$ values 
of the PEG 400, glycerol, PVP-I, copovidone, ethanol and HFA 134a were 14.9, 34.9, 5.1, 5.1, 24.3 and 9.5, respectively. The measured $\varepsilon$ value of PVP-I (5.1) was similar to that of copovidone (5.1) at the same frequency $\left(5 \times 10^{6} \mathrm{~Hz}\right)$. This meant that the $\varepsilon$ value was mainly dependent on the polymer despite the presence of iodine molecule. In a solution-based formulation, if the $\varepsilon$ value of the drug was close to that of the solvent system, the drug would be completely dissolved. Thus, PVP-I will not dissolve in propylene glycol (37.9) and glycerol (34.9), and for this reason, propylene glycol was excluded in the formulation due to the high value of $\varepsilon$ and glycerol was used at concentration of $1 \%(\mathrm{~m} / \mathrm{m})$ in the formulation. Hence, the PVP-I must be first dissolved in the mixed solvents that have a reduced $\varepsilon$ value of their solvent system (17). Based on the "like dissolves like" principle, the concentration of the co-solvent and their $\varepsilon$ values were crucial factors required to dissolve the PVP-I, therefore the $\varepsilon$ value of the solvent systems must be close to the $\varepsilon$ of the PVP-I (18). The production of a topical spray by a solution-based pressurized metered dose inhaler (pMDI) method with HFA 134a was started by preparing the product concentrate to have an $\varepsilon$ value close to that of the HFA 134a propellant. From the observations, PVP-I $10 \%$ $(\mathrm{m} / \mathrm{m})$ dissolved in the propellant system (4 mL of ethanol and $8 \mathrm{~mL}$ of HFA 134a) produced a clear solution. We had optimized the formulation by varying the ethanol, copovidone and PEG 400 as shown in Table I. The total number of formulations was 27. The $\varepsilon$ values of all formulations (product concentrate - formulation without propellant) were within a narrow range (of between 12 and 13). This indicated that the $\varepsilon$ value of the product concentrate was decreased compared to that of the propellant and ensured the formation of a clear solution of the PVP-I spray.

\section{Factorial design}

A three factors, multi-levels full factorial design was employed to optimize and investigate the effect of various concentrations of ethanol, copovidone, and PEG 400 on the viscosity and surface tension of the PVP-I spray. The viscosity and surface tension of the formulation have an effect on the physical characteristics of aerosol spray and quality of the film formation $(19,20)$. If the formulation has high viscosity and surface tension, it would be very difficult to spray and cannot form a thin film. On the other hand, the formulation with low viscosity and surface tension would not be able to form an acceptable film. The effects of independent variables (concentration of ethanol, copovidone and PEG 400) on the responses (surface tension and viscosity) were modeled using multiple regressions. In this mathematical approach, the responses were represented by the following regression equations:

$$
\begin{aligned}
& Y_{\text {viscosity }}=32.56-11.49 X_{1}+18.83 X_{2}+2.99 X_{3}-9.29 X_{1} X_{2}-1.44 X_{1} X_{3}+1.22 X_{2} X_{3} \\
& Y_{\text {surface tension }}=23.11-0.47 X_{1}+0.38 X_{2}+0.56 X_{3}+0.22 X_{1} X_{2}-0.04 X_{1} X_{3}-0.38 X_{2} X_{3}
\end{aligned}
$$

where $X_{1}, X_{2}$ and $X_{3}$ were the concentration of ethanol, copovidone and PEG 400 respectively.

The viscosity and surface tension of the PVP-I spray was dependent on the formulation excipients. Equation (6) showed a good correlation coefficient $\left(R^{2}=0.954\right)$ whereas equation (7) gave a lower correlation coefficient $\left(R^{2}=0.752\right)$.

The most influential parameters on the viscosity were the contents of ethanol and copovidone which can be seen from the high coefficients of $X_{1}$ and $X_{2}$ (Fig. 2). The surface 

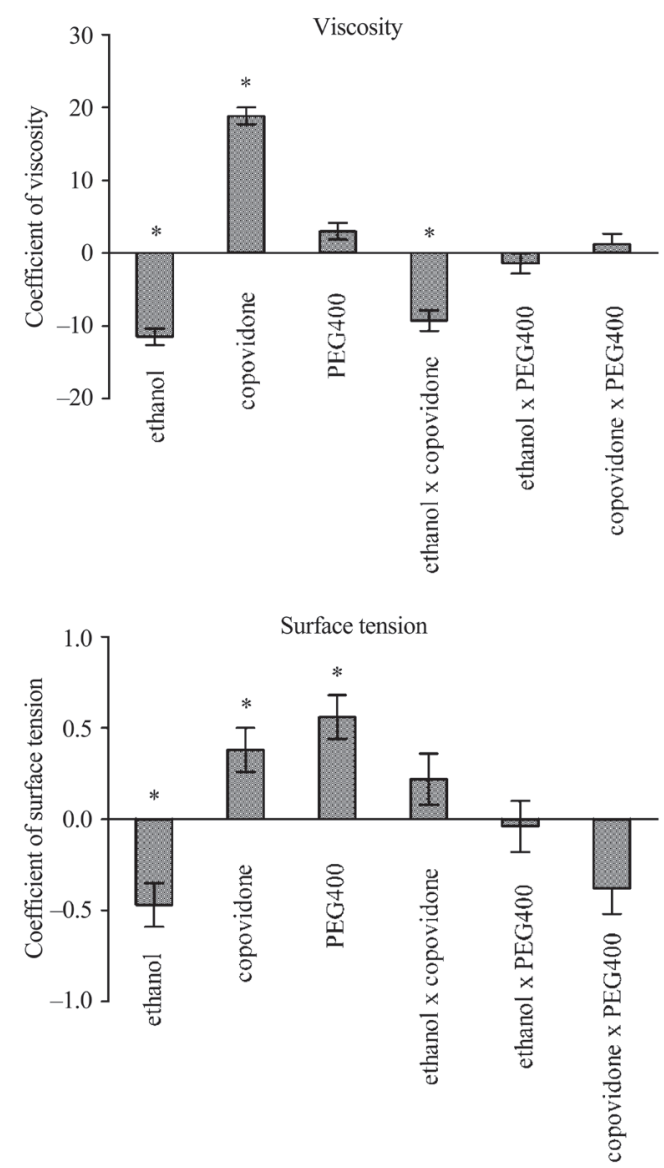

Fig. 2. Coefficients of viscosity ( \pm standard error, $n=27$ ) and surface tension ( \pm standard error, $n=27$ ). * Statistically significant.

tension of the formulations was equally affected by all three parameters (ethanol, copovidone and PEG400) as shown in Fig. 2. The negative value of the coefficient indicated an inverse relationship between ethanol and the viscosity and surface tension.

\section{Evaluation of PVP-I topical spray formulation}

PVP-I topical spray formulations $(N=27)$ were prepared according to Table I and the evaluation results are presented below.

Density and viscosity of PVP-I formulations

In the present study, the density of all the PVP-I $(10 \%(\mathrm{~m} / \mathrm{m})$ spray formulations) was around $0.9 \mathrm{~g} \mathrm{~cm}^{-3}$. The viscosity of the PVP-I formulations was within the range of 11.9- 
$85.9 \mathrm{mPa}$ s. All the formulations that had high content of copovidone $(>16.7 \%, \mathrm{~m} / \mathrm{m})$ and a high content of PEG $400(>6.4 \%, \mathrm{~m} / \mathrm{m})$ had high viscosity. As the viscosity of the formulations affected the spray performance, it was difficult to spray PVP-I and this resulted in a low content of PVP-I. It was anticipated, that the viscosity of the PVP-I solutions was a function of both the molecular weight and the concentration of the polymer (Fig. 3a and 4a). When the concentration of the copovidone was increased, the viscosity of the PVP-I formulation also increased.

\section{Surface tension}

Surface tension indicated the spreadability of the formulation on the skin. The surface tension of the PVP-I formulations were all between $20.3-24.6 \mathrm{mN} \mathrm{m}^{-1}$. All PVP-I formulations showed a similar low surface tension (Fig. $3 \mathrm{~b}$ and $4 \mathrm{~b}$ ) and this indicated that the formulations spread well on the skin. The surface tension of a liquid is determined by the forces of attraction between the molecules that make up the liquid. In the depths of a volume of liquid, each molecule is surrounded on all sides by other similar molecules; the forces between them balance out and the entire mass is in equilibrium. If the coating surface tension is greater than the substrate surface energy, then the coating will not spread out and form a film. However, an increase of the substrate surface energy will reach a stage at which the film will spread out and form a film. Further increase in the surface energy of the substrate will result in an easier formation of a film adhesion $(21,22)$.
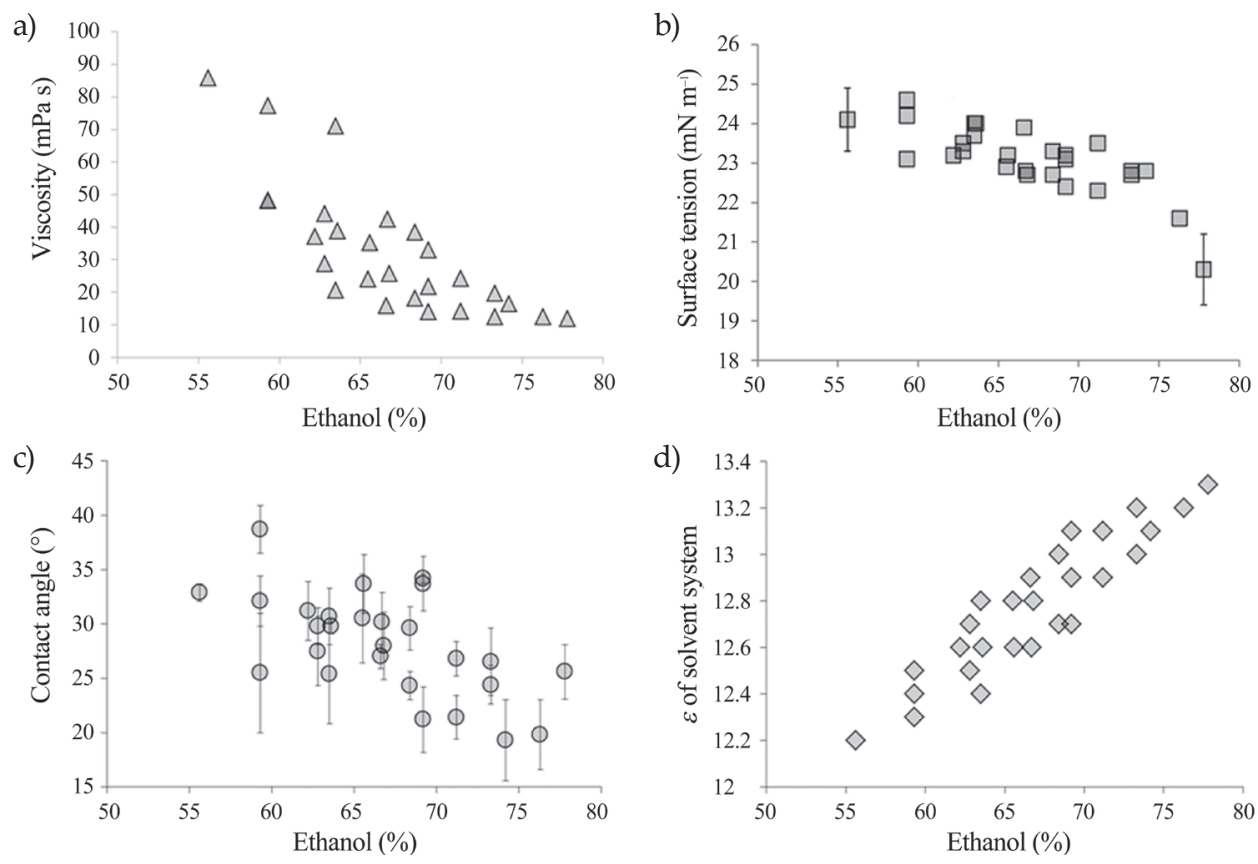

Fig. 3. a) Viscosity, b) surface tension, c) contact angle, and d) $\varepsilon$ of the solvent system of the PVP-I formulations containing different concentrations of ethanol. 


\section{Contact angles}

The contact angle value was used to predict the spreading efficacy of the formulation when applied to the skin. If $\theta$ was less than $90^{\circ}$ the liquid tended to spread out over the surface and when the liquid formed a thin film, $\theta$ tends to become zero (23). The contact angles of the 27 PVP-I formulations were between 19.3 and $38.7^{\circ}$ (Fig. 3c and 4c). This value predicted the formulation that had a good spreadability when it was applied on the skin. Therefore, the PVP-I formulations were able to spread and form a thin film on the skin surface.

pH value

It was important to make sure that the $\mathrm{pH}$ of the PVP-I system remained acidic to prevent the dissociation of the complex (24). The effective $\mathrm{pH}$ of the solutions of any commercial product was in the range of 3 to 6 (25). In this study, the $\mathrm{pH}$ of all pressurized formulations cannot be determined directly because the formulations are sealed in a closed system. The $\mathrm{pH}$ of the spray products was found to be in the range of 6 to 7 . The $\mathrm{pH}$ of Siribuncha ${ }^{\circledR}$ PVP-I solution was lower than the spray product due to the suppression of ionization in the ethanolic solution. When the ethanol was dried up, the $\mathrm{pH}$ increased. This $\mathrm{pH}$ was close to the $\mathrm{pH}$ of the human skin that typically ranged from 4.5 to 6.0. Thus, the $\mathrm{pH}$ data (6 to 7) of the PVP-I spray preparation was acceptable for a topical preparation.

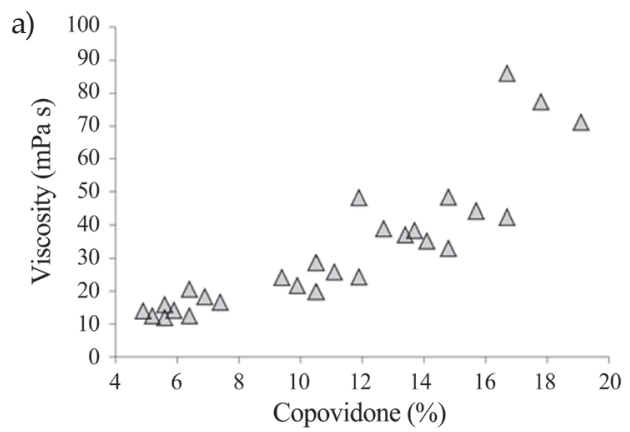

b)
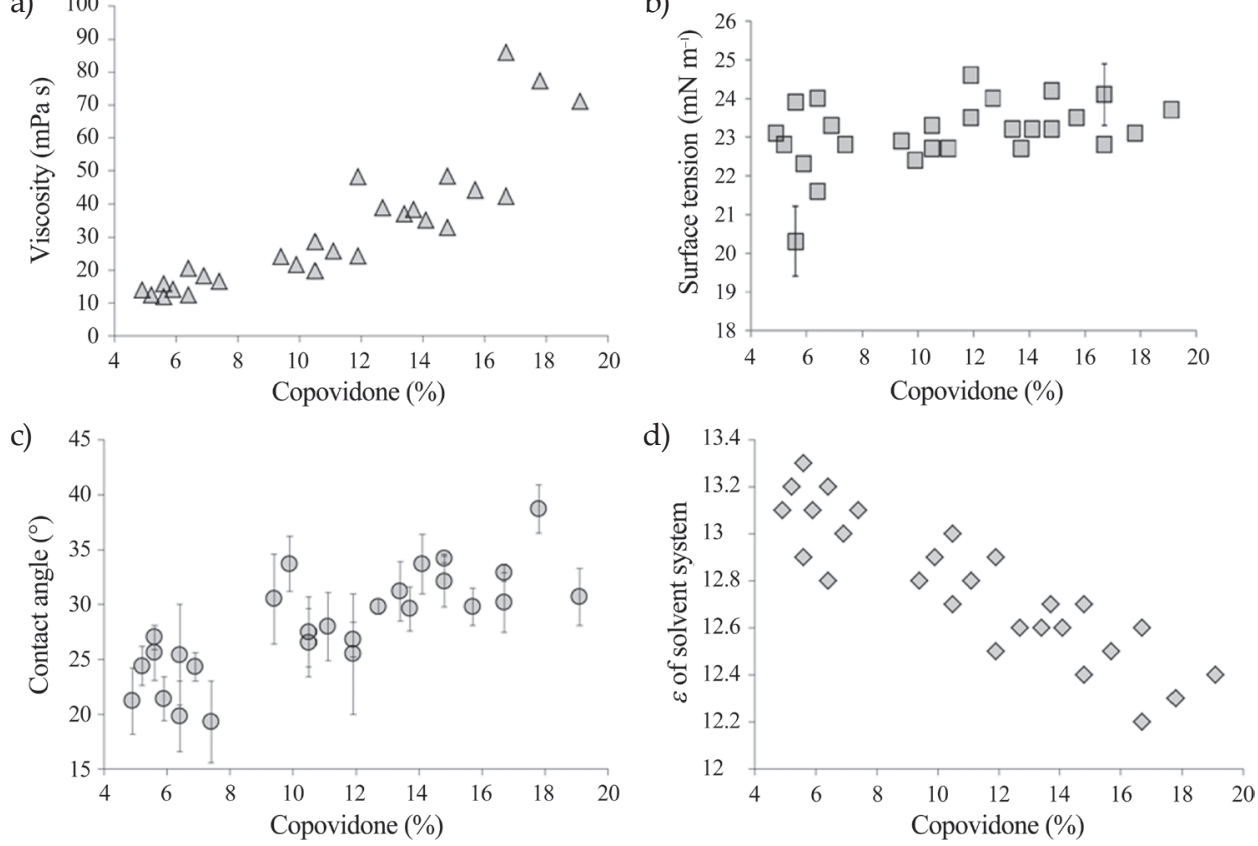

Fig. 4. a) Viscosity, b) surface tension, c) contact angle, and d) $\varepsilon$ of solvent system of the PVP-I formulations containing different concentrations of copovidone. 
Also, it is well known that an acidic $\mathrm{pH}$ will be harmful to bacteria and fungi (26) and this will promote the microbicidal activity of PVP-I.

Stability of PVP-I spray

The mass stability of the PVP-I formulations was tested by storing at room temperature up to 3 months. The loss of mass from all formulations was less than $1.5 \%$ according to leakage test as specified in USP under general chapter $<601>(14)$. This experiment was performed to ensure that the manufacturing and packaging procedures of the spray were robust. In addition, the packaging of the spray was supposed to protect it from the outside environment.

a)

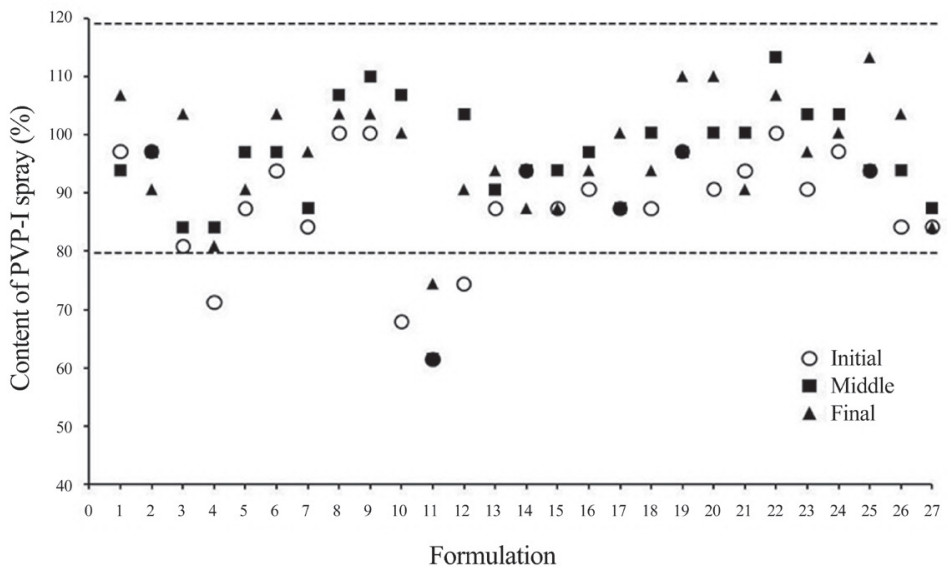

b)

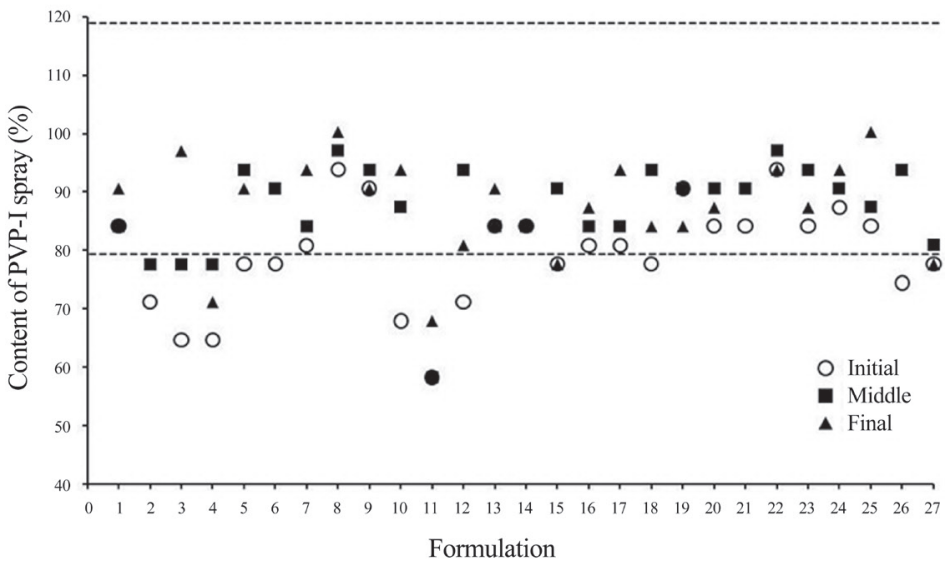

Fig. 5. Iodine content of the PVP-I spray at: a) the initial activation, b) after storage at $25{ }^{\circ} \mathrm{C}$ for 3 months. Doses were collected at the beginning, mid time, and end of the PVP-I. The dashed lines are the upper limit (120\%) and the lower limited ( $80 \%)$ of the iodine content. 
A. Sa et al.: Quantitative analysis of povidone-iodine thin films by X-ray photoelectron spectroscopy and their physicochemical properties, Acta Pharm. 67 (2017) 169-186.

\section{Content of iodine in the PVP-I spray formulations}

The 27 formulations were tested for their content of iodine in the PVP-I spray by actuation of the valve initially and after 3 months of storage. The amount of the active ingredient delivered by actuation of the valve with respective to the formulations (F1, F7- F9, F13, F14, F16, F17, F19-F25) were within the acceptable range (80-120 \%) as described in the British Pharmacopoeia (27) and as shown in Fig. 5. For the remaining 12 formulations the amount of drug fluctuated from 58 to $105 \%$, but most of these formulations provided a much lower dose that was not within either of the acceptable ranges. Formulation F8 [ethanol $59 \%$ $(\mathrm{m} / \mathrm{m})$, copovidone $18 \%(\mathrm{~m} / \mathrm{m})$ and PEG $40012 \%(\mathrm{~m} / \mathrm{m})$ ] provided the highest delivery of iodine, this indicated that the high content of the film forming agent had no effect on the actuator and valve to release the active ingredient. The lower content of iodine may be caused by a high ethanol content which immediately evaporated. Initially for all the formulation, the iodine contents were within the range of $80-100 \%$ of the labeled amount (Fig. 5a). After storage at room temperature for 3 months, the iodine contents dropped but were still within the range of $80-94 \%$ of the labeled amount. The content of iodine of all formulations at various time points showed consistent values (Fig. 5b) and showed the homogeneity and uniformity of the PVP-I formulations. The content of PVP-I in the formulation with a low content of ethanol, a high content of copovidone and a medium content of PEG 400 (formulation F8) showed an iodine content that was close to $100 \%$ so that this formulation was selected as the optimal one and was subjected to further characterization.

\section{XPS determination of iodine form}

Iodine form $\left(\mathrm{I}_{2}\right.$ and $\left.\mathrm{I}^{-}\right)$was compared between PVP-I spray formulation (selected formulation F8) and the iodine spray. Iodine and iodides $\left(\mathrm{I}^{-}\right)$were determined by XPS analysis. The ratio of the iodine forms was different between the two formulations (Fig. 6a-c). There were two dominant iodine peaks with the binding energies of 618.04 and $620.22 \mathrm{eV}$, which were assigned to the ionized and unionized form of iodine, respectively. The ionized form to the unionized form ratio of the PVP-I spray and $\mathrm{I}_{2}$ spray was 88:12 and 67:33, respectively. These ratios could indicate the capability of the antibacterial effect.

\section{Distribution of droplet size and thickness of the PVP-I spray formulations}

Film formulations are available in various thickness that ranges from $\mu \mathrm{m}$ to $\mathrm{nm}$ when prepared by different methods using one or more polymers. Films are ideal dressing materials and are commercially available. Films with homogeneous polymeric network structures have been used to cover the damaged area that protects the wound from external factors $(28,29)$. In this study, the droplet sizes of all the formulations were in the range of 1.6-18.5 $\mu \mathrm{m}$. The thin films produced by spraying were smooth with a uniform distribution of iodine that was reflected by the color (Fig. 7a) and with the thickness of 500-900 nm. Formulations F14, F15, F19-F21, and F24 (included a medium to high content of ethanol and PEG 400 with a low to medium content of copovidone) showed a low spreadability of iodine droplet because some of the iodine did not dissolve completely in the solvent mixture. The iodine content in the spray spread evenly over the sprayed surface and the droplets completely covered the surface uniformly as a continuous thin film. Copovidone had good binding and film-forming properties with an affinity to hydrophobic surfaces with a rela- 
a)

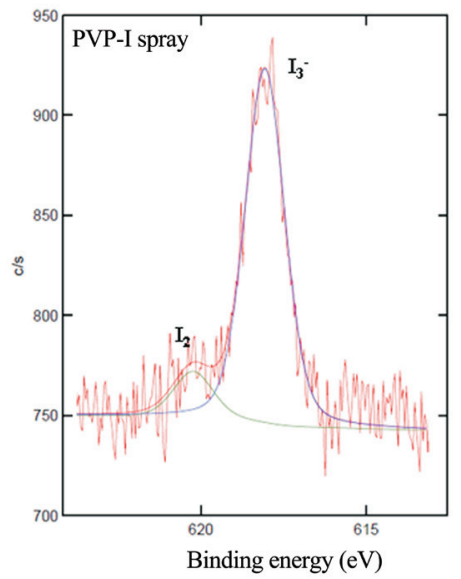

b)

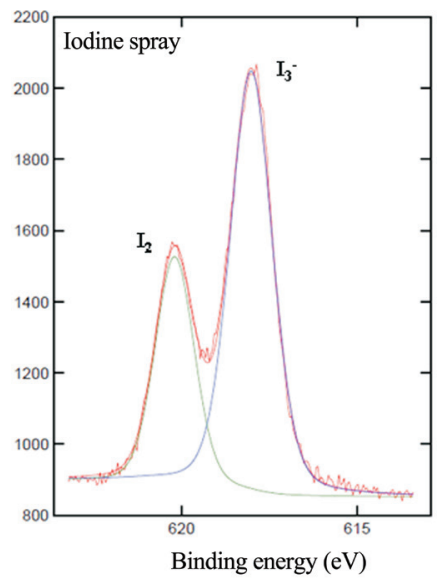

c)

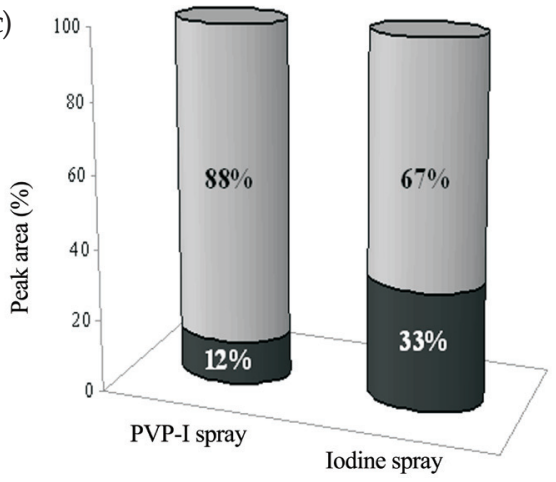

$\square$ Polyiodides

प Iodine

Fig. 6. Comparison of XPS analysis between: a) PVP-I spray and b) iodine spray, c) the peak area percentage of iodides (ionized form) and iodine (unionized form) in different formulations.

tive low hygroscopicity. Due to these important properties, copovidone can be used as a film-forming agent in sprays and as a matrix. We found that the formulation F8 dried within $20 \mathrm{~s}$, which was faster than the other formulations ( $30 \mathrm{~s})$. The PVP-I film formed after spraying on a glass slide was easily removed with water. This illustrates the advantage of using copovidone and PEG 400 to ensure good binding properties and a higher plasticity when used in the liquid dosage form apart from the sprays (24). Formulation F8 produced the uniform droplet size and an ideal thin film of PVP-I when sprayed onto a glass surface (Fig. 7b).

\section{Antibacterial activity of the PVP-I topical spray formulation and cell viability}

PVP-I formulation (formulation F8) prepared in this study exhibited increased antibacterial activity than pure PVP-I as measured by the zone of inhibition. PVP-I had a better 
a) Topography - Scan foward Line fit

b)
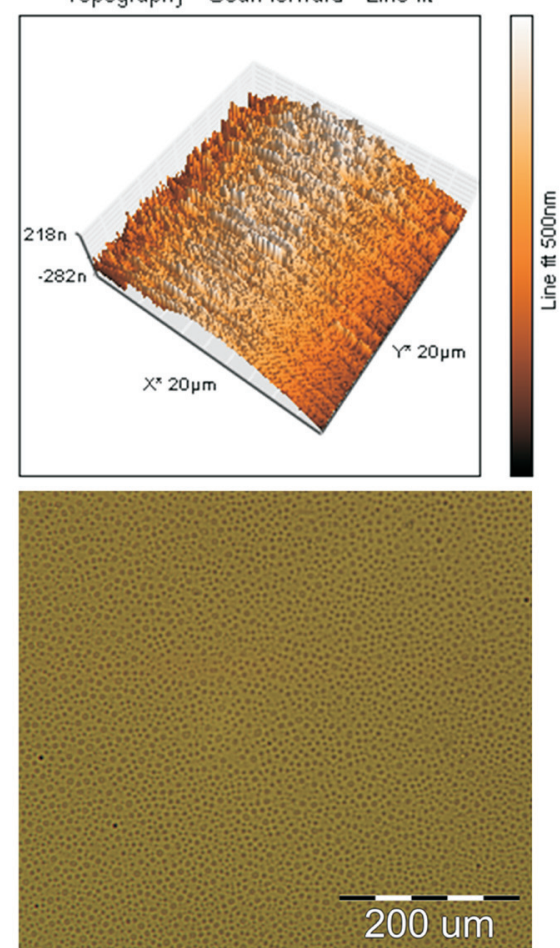

Fig. 7. a) AFM image of a film from the PVP-I formulation F8 obtained in a non-contact mode, b) micrographs from a light microscope $(500 \times)$.

antibacterial effect on Gram-positive than Gram-negative bacteria. According to the inhibition zone study and the content of PVP-I on a paper disc, the PVP-I spray exhibited superior antibacterial activity than the positive control (vancomycin for Gram-positive and gentamicin for Gram-negative bacteria) especially on S. aureus and S. epidermidis. However, the activity against $P$. aeruginosa was slightly lower. It was concluded that the formulations had been successfully developed to use as antibacterial skin preparations.

The MIC and MBC values of the PVP-I spray formulation F8 and Siribuncha ${ }^{\circledR}$ PVP-I solution were determined for both Gram-positive (S. aureus and S. epidermidis) and Gramnegative bacteria (P. aeruginosa). The MIC values of the PVP-I spray formulation F8 was 0.16, 0.32 and $0.32 \%(m / V)$ for S. aureus, S. epidermidis and P. aeruginosa, respectively whereas the $M B C$ values for this formulation was $0.32 \%(m / V)$ for all the bacteria. In addition, the Siribuncha ${ }^{\circledR}$ PVP-I solution had MIC values of $0.08,0.04$ and $0.04 \%(m / V)$ for S. aureus, S. epidermidis and $P$. aeruginosa respectively and the $M B C$ values of the Siribuncha ${ }^{\circledR}$ PVP-I solution was $0.16 \%(\mathrm{~m} / \mathrm{V})$ for all the bacteria. The MICs for vancomycin (positive control for Gram-positive bacteria) and gentamicin (positive control for Gram-negative bacteria) were 1 and $4 \mu \mathrm{g} \mathrm{mL}^{-1}$ respectively. The formulation showed promising antibacterial activity as compared to the commercial PVP-I solution. 
The viability of $\mathrm{BJ}$ and $\mathrm{HaCaT}$ cell lines incubated with the PVP-I spray formulation and the commercial PVP-I solution at a concentration of $0.32 \%(\mathrm{~m} / \mathrm{V})$ were assessed to have an insight on the toxicity of the formulations. More than $80 \%$ survival was recorded for both the $\mathrm{BJ}$ and $\mathrm{HaCaT}$ cell lines even after treatment with glycerol, ethanol, copovidone, PEG mixtures (free drug) and the PVP-I spray formulation. This confirmed the reduced toxicity of the developed PVP-I spray formulation. In the case of the commercial PVP-I solution, the viability of the BJ and HaCaT cell line rapidly decreased to 9.13 and $16.39 \%$, respectively.

The amount of unionized iodine did not only indicate the permeability to the bacterial cell wall but also showed the toxicity of the formulations because the unionized form can also permeate the human skin. Due to the fact that PVP-I serves as a sustained release reservoir for iodine and analysis of PVP-I spray with XPS found that the iodine in the ionized form was much higher than the unionized form. Therefore the PVP-I spray leads to a lower toxicity to the skin cells in vitro compare to the Siribuncha ${ }^{\circledR}$ PVP-I solution.

PVP-I was effective against all the three test bacteria. The broad spectrum of the antimicrobial activity of PVP-I has been well documented and its efficacy, particularly, in relation to resistant microorganisms such as S. aureus, S. epidermidis (4). Its microbicidal activity has a non-specific mode of action that causes irreversible damage to the microorganism with no tendency to cause resistance. However, PVP-I can react with materials other than microbes and thus its germicidal efficacy can be reduced (25).

Several studies have exemplified the usage of iodine to treat or prevent wound infections (30) and are still finding a use since its discovery. In this study, the PVP-I formulations effectively controlled the growth of the standard and clinical isolates of $S$. aureus, $S$. epidermidis and P. aeruginosa which are the predominant causes of wound infections.

Table II. Antibacterial activity and cytotoxicity of PVP-I spray and commercial PVP-I solution

\begin{tabular}{ccccccccc}
\hline & \multicolumn{3}{c}{$M I C(\%, m / V)$} & \multicolumn{3}{c}{$M B C(\%, m / V)$} & \multicolumn{2}{c}{ Cell viability (\%) } \\
\cline { 2 - 9 } Formulation & SA & SE & PA & SA & SE & PA & HaCaT & BJ \\
\hline $\begin{array}{c}\text { PVP-I spray } \\
\text { (formulation F8) } \\
\begin{array}{c}\text { Commercial } \\
\text { PVP-I solution }\end{array}\end{array}$ & 0.16 & 0.32 & 0.32 & 0.32 & 0.32 & 0.32 & $82.8 / 21.0^{\mathrm{a}}$ & $94.7 / 14.9^{\mathrm{a}}$ \\
\hline
\end{tabular}

SA - S. aureus; SE - S. epidermidis; PA - P. aeruginosa; HaCaT - keratinocyte cells; BJ - fibroblast cells. Viability of HaCaT and BJ cells was at the concentrations of 0.16 and $0.32 \%(\mathrm{~m} / \mathrm{V})^{\mathrm{a}}$ and $0.04,0.08$, and $0.16 \%(\mathrm{~m} / \mathrm{V})^{\mathrm{b}}$ respectively.

\section{CONCLUSIONS}

PVP-I spray solutions containing PVP-I $10 \%(\mathrm{~m} / \mathrm{m})$, with copovidone as a film forming agent, ethanol as a co-solvent, PEG 400 and glycerol as an excipient, have been successfully developed. The delivered content of iodine and physicochemical properties showed that these formulations were acceptable and suitable for skin treatment. Analysis of the PVP-I spray with XPS confirmed that the iodine in its ionized form was higher than the unionized form and this may indicate a low toxicity to skin cells. The cytotoxicity study 
A. Sa et al.: Quantitative analysis of povidone-iodine thin films by X-ray photoelectron spectroscopy and their physicochemical properties, Acta Pharm. 67 (2017) 169-186.

confirmed that the developed PVP-I spray formulation had a lower toxicity than the commercial PVP-I solution to keratinocytes and fibroblasts in vitro. The formulation that consists of low content of ethanol $(59 \%, \mathrm{~m} / \mathrm{m})$, a high content of copovidone $(18 \%, \mathrm{~m} / \mathrm{m})$ and medium content of PEG $400(12 \%, \mathrm{~m} / \mathrm{m})$ showed the uniform droplet size and produced the ideal ultrathin film of PVP-I when sprayed onto a glass slide.

Acknowledgements. - This work was supported by the National Research Council of Thailand and the Prince of Songkla University National Research University Project of Thailand's Office of the Higher Education Commission and Graduate School, Prince of Songkla University. Thanks also to Dr. Brian Hodgson for assistance with the English. The authors declare no conflict of interest.

\section{REFERENCES}

1. H. Kampf and A. Kramer, Epidemiologic background of hand hygiene and evaluation of the most important agents for scrubs and rubs, Clin. Microbiol. Rev. 17 (2004) 863-893; DOI: 10.1128/ CMR.17.4.863-893.2004.

2. O. Aviv, N. Laout, S. Ratner, O. Harik, K. R. Kunduru and A. J. Domb, Controlled iodine release from polyurethane sponges for water decontamination, J. Control. Release. 172 (2013) 634-640; DOI: 10.1016/j.jconrel.2013.09.018.

3. K. Yuichiro, K. Hiroaki and M. Shigehiro, Orally Disintegrable Solid Preparation Comprising Povidone-iodine, U.S. Pat. 20080227849, 28 Sep 2008.

4. P. Durani and D. Leaper, Povidone-iodine: use in hand disinfection, skin preparation and antiseptic irrigation, Int. Wound. J. 5 (2008) 376-387; DOI: 10.1111/j.1742-481X.2007.00405.x.

5. D. O. Lowe, S. R. Knowles, C. J. Railton and N. H. Shear, Povidone-iodine-induced burn: case report and review of the literature, Pharmacotherapy 26 (2006) 1641-1645; DOI: 10.1592/phco.26.11.1641.

6. G. Waldemar, Iodine and Iodine Compounds, in Disinfection Sterilization, and Preservation (Ed. S. S. Block), Lippincott Williams \& Wilkins, Philadelphia 2001.

7. S. Aronson and S. B. Wilensky, Complex formation in 2-polyvinylpyrrolidine-iodine solution, $J$. Polymer Sci.: Part A: Polymer Chemistry 26 (1988) 1259-1262.

8. F. K. Field and M. D. Kerstein, Overview of wound healing in a moist environment, Am. J. Surg. 167 (1994) 2S-6S.

9. J. Flynn, Povidone-iodine as a topical antiseptic for treating and preventing wound infection: a literature review, Br. J. Community. Nurs. 8 (2003) S36-S42; DOI: http://dx.doi.org/10.12968/ bjcn.2003.8.Sup2.11555.

10. K. C. Chang, Y. C. Yeh and J. T. Lue, Measurement of the dielectric constant of zinc metallic nanoparticles at various frequencies, Measurement 45 (2012) 808-813; DOI: 10.1016/j.measurement.2011.06.021.

11. J. Holoubek, Some applications of light scattering in materials science, J. Quant. Spectrosc. Radiat. Transfer. 106 (2007) 104-121; DOI: 10.1016/j.jqsrt.2007.01.013.

12. Operating Instruction of pH meter FEP20, Mettler-Toledo AG, Analytical, CH6603 Schwerzenbach, Switzerland.

13. J. Ninbovorl, S. Sawatdee and T. Srichana, Factor affecting the stability and performance of ipratropium bromide; fenoterol hydrobromide pressurized-metered dose inhalers, AAPS PharmSciTech. 14 (2013) 1294-1302; DOI: 10.1208/s12249-013-0024-4.

14. United State Pharmacopeia 34, National Formulary 29, US Pharmacopeial Convention, Rockville 2011.

15. W. N. Wang, A. Purwanto, I. W. Lenggoro, K. Okuyama, H. Chang and H. D. Jang, Investigation on the correlations between droplet and particle size distribution in ultrasonic spray pyrolysis, Ind. Eng. Chem. Res. 47 (2008) 1650-1659; DOI: 10.1021/ie070821d. 
16. P. Kim, J. K. Sohng, C. Sung, H. S. Joo, E. M. Kim, T. Yamaguchi, D. Park, B. G. Kim, Characterization and structural identification of an antimicrobial peptide, hominicin, produced by Staphylococcus hominis MBBL 2-9, Biochem. Biophys. Res. Commun. 399 (2010) 133-138; DOI: 10.1016/j. bbrc.2010.07.024.

17. P. Wang and A. Anderko, Computational of dielectric constants of solvent mixtures and electrolyte solutions, Fluid Phase Equilib. 186 (2001) 103-122; DOI: 10.1016/S0378-3812(01)00507-6.

18. L. V. Allen, N. G. Popovich and H. C. Ansel, Ansel's Pharmaceutical Dosage Forms and Drug Delivery Systems, $9^{\text {th }}$ ed., Lippincott Williams \& Wilkins, China 2011.

19. V. S. Kulkarni, C. Shaw, Essential Chemistry for Formulations of Semisolid and Liquid Dosages, Academic Press, San Diego 2016, pp.71-72.

20. M. C. Gohel, S. A. Nagori, Fabrication of modified transport fluconazole transdermal spray containing ethyl cellulose and Eudragit ${ }^{\circledR}$ RS100 as film formers, AAPS PharmSciTech. 10 (2009) 684691; DOI: 10.1208/s12249-009-9256-8.

21. H. J. Busscher, A. H. Weerkamp, H. C. Mei, A. W. Pelt, H. P. Jong and J. Arends, Measurement of the surface free energy of bacterial cell surfaces and its relevance for adhesion, Appl. Environ. Microbiol. 48 (1984) 980-983.

22. W. Zheng, Surface Wetting Characteristics of Rubbed Polyimide Thin Films, Polymer Thin Films (Ed. A. A. Hashim), In Tech, Croatia 2010, Available from:http://www.intechopen.com/books/polymerthin-films/surface-wettingcharacteristics-of-rubbed-polyimide-thinfilms, 2010, access date June $1,2015$.

23. E. Chibowski and M. Jurak, Comparison of contact angle hysteresis of different probe liquids on the same solid surface, Colloid. Polym. Sci. 291 (2013) 391-399; DOI: 10.1007/s00396-012-2777-9.

24. E. S. Barabas and H. G. Brittain, Povidone-iodine, Analytical Profiles of Drug Substances and Excipients. 25 (1998) 341-462.

25. S. P. Kumar, R. P. Babu, J. G. Reddy and A. Uttam, Povidone iodine-revisited, IJDA. 3 (2011) 617620; DOI: 10.5866/3.3.617.

26. K. Chikakane and H. Takahashi, Measurement of skin $\mathrm{pH}$ and its significance in cutaneous diseases, Clin. Dermatol. 13 (1995) 299-306; DOI: 10.1016/0738-081X(95)00076-R.

27. British Pharmacopoeia, Her Majesty's Stationery Office, London 2011.

28. P. R. P. Verma and S. S. Iyer, Controlled transdermal delivery of propranolol using HPMC matrices: design and in-vitro and in-vivo evaluation, J. Pharm. Pharmacol. 52 (2000) 151-156; DOI: 10.1211/0022357001773797.

29. T. S. Stashak, E. Farstvedt and A. Othic, Update on wound dressings: Indications and best use, Clin. Tech. Equine. Pract. 3 (2004) 148-163; DOI: 10.1053/j.ctep.2004.08.006.

30. H. Vermeulen, S. J. Westerbos and D. T. Ubbink, Benefit and harm of iodine in wound care: a systematic review, J. Hosp. Infect. 76 (2010) 191-199; DOI: 10.1016/j.jhin.2010.04.026. 